\title{
Can ozone or violet light improve the color change or physicochemical properties of hydrogen peroxide- bleached tooth?
}

\author{
Nayara Rodrigues Nascimento Oliveira Tavares @1, Alexia da Mata \\ Galvão 1, Lia Dietrich [1, Roberta Furtado Carvalho [2, \\ Robinson Sabino Silva $\mathbb{Q}^{3}$, André Luis Faria e Silva $\mathbb{Q}^{4}$, Gisele \\ Rodrigues da Silva ${ }^{1}$
}

\begin{abstract}
This study investigated the bleaching effectiveness and the physicochemical effects on enamel of violet light and ozone, associate or not to hydrogen peroxide, compared to 35\%-hydrogen peroxide. Enamel-dentin blocks from human molars were randomly allocated to receive one of the following bleaching protocols $(\mathrm{n}=15)$ : (HP) 35\%-hydrogen peroxide, (VL) violet light, $(\mathrm{OZ})$ ozone, the association between hydrogen peroxide with ozone $(\mathrm{OZ}+\mathrm{HP})$ or violet light $(\mathrm{VL}+\mathrm{HP})$. All protocols were performed in two sessions with a $48 \mathrm{~h}$ interval. Color (spectrophotometer) and mineral composition (Raman spectroscopy) were measured before and after the bleaching. Color changes were calculated by $\Delta \mathrm{E}_{\mathrm{ab}}, \Delta \mathrm{E}_{00}$, and whitening index (WI). The surface roughness was measured with an atomic force microscope. Data were analyzed by One-way or Two-way repeated measure ANOVA followed by the Tukey's test ( $\alpha=0.05$ ). The lowest color change values (either measured by WI, $\Delta \mathrm{E}_{\mathrm{ab}}$, or $\Delta \mathrm{E}_{00}$ ) were observed for VL and OZ used with no HP. Violet light associate with HP was unable to improve the color changes observed for the peroxide alone, in combination with $\mathrm{OZ}$ and $\mathrm{HP}$, the highest color changes were verified. Regardless of bleaching protocol, the bleached enamel presented higher contents of $\mathrm{PO}_{4}$ and $\mathrm{CO}_{3}{ }^{-2}$ than those observed at baseline. All bleaching protocols resulted in similar enamel surface roughness. Both the VL and the OZ caused reduced effects on the enamel color change when used alone. The ozone therapy improved the bleaching effect in the group that received the association of HP.
\end{abstract}

\section{Introduction}

Tooth bleaching is a common procedure used to improve the esthetic appearance of patients for being a simple, effective, and conservative method. Patients submitted to tooth bleaching have better psychological adjustment and social relationships.(1)

Although home-applied techniques are largely used by patients, in-office bleaching procedures remain being performed, especially when the use of trays is not indicated. Due to the use of highlyconcentrated peroxides, a higher risk of tooth sensitivity has been observed at in-office techniques than those seen with treatment performed at home.(1) The presence of peroxides and their subproducts can reach the pulp chamber, activating the TRPA1 channel (transient receptor potential cation channel with ankyrin domain-type), associated with pain caused by oxidizing agents, including the hydrogen peroxide.(2) Furthermore, some effects on enamel such as roughness and demineralization increase and mechanical properties decrease have been verified after the use of highly-concentrated peroxides over the enamel.(3) Therefore, several studies have proposed other tooth bleaching techniques, including the use of reduced peroxide concentrations, whiteners of higher $\mathrm{pH}$ and/or containing calcium or desensitizers agents,(4) and the use of violet light, $(5,6)$ or ozone. $(7,8)$ All these protocols claim for reducing or minimizing the tooth sensitivity or physicochemical damages to the dental structures.

The violet light-emitting diodes (LED) and the ozone have been described as techniques that allows bleaching associated or not to peroxides, and it can be used even for patients with dentin hypersensitivity. $(5,6)$ The wavelength range of violet light coincides with the pigment molecules absorption peak. Pigmented molecules are photoreceptors highly reactive to light and their chains are long, with electron-shifting chemical connection sequences, susceptible to the absorption of shorter wavelengths, such as violet LED light. VL source seems to have the potential to bleach the dental structure without HP use due to the interaction between light $(405-410 \mathrm{~nm})$ and pigments that occur 
selectively, resulting in the breakdown of macromolecules into smaller and less pigmented types that absorb less light, resulting in tooth bleaching. (5) The violet LED light $(405-410 \mathrm{~nm})$ can also be used in photo-accelerated bleaching procedures using different concentrations of HP.(5) The effect of a conventional bleaching technique combined with violet LED light, known as the hybrid technique, has been studied and the results suggested an increase in bleaching efficacy.(5)

The ozone (trioxygen) is a strong oxidizing agent with similar bleaching ability to the one of the hydrogen peroxide $37.5 \%$ or the carbamide peroxide $45 \%$, including on tetracycline-stained teeth.(7-9) This oxidizing action is responsible for the rapid release of oxygen molecules, thus oxidizing the components responsible for tooth discoloration, breaking the chromophore groups into smaller molecules, and acting by three mechanisms in the bleaching process (bonding, replacement, or cleavage). O3 also proved to be effective in association with HP, reducing the time of exposure of dental tissues to the gel, to maintain the effectiveness of whitening results with HP, thus reducing the possibility of tooth sensitivity symptomatology seen as a secondary effect of prolonged tooth exposure to HP.(8)

Since the knowledge gap regarding violet light and ozone effectiveness on tooth bleaching procedures, this study aims at assessing the bleaching and physicochemical effects of violet light and ozone associate or not to hydrogen peroxide on enamel compared to the effects caused by the use of $35 \%$-hydrogen peroxide for the same purpose. The null hypothesis was that: the use of ozone or violet light does not interfere in the bleaching effectiveness (1), and does not alter roughness (2) or mineral composition (3) of the bleached enamel when compared to the use of 35\%-hydrogen peroxide alone.

\section{Material and Methods}

\section{Sample Size}

To determine the size of the sample, the main outcome was considered $\Delta \mathrm{E}_{\mathrm{ab}}$. The calculation was based on the lowest acceptability threshold bounder from a previous study.(10)Considering a minimum detectable difference of 2.66 in the mean values, power test of 0.8 , and $\alpha=0.05$, for 5 experimental groups to be submitted to ANOVA test. The calculation was performed using the statistical software SigmaStat v.3.5 (Systat Software Inc., Chicago, IL, USA) and the required sample size was determined to be $\mathrm{n}=15$.

\section{Specimens Preparation}

The present study was conducted in compliance with the Declaration of Helsinki and following the human ethical guidelines. The Institutional Ethics Committee of the Patos de Minas College approved the study (protocol \# 79760717.5.0000.8078). Written informed consent forms were obtained from all subjects.

Teeth shade was examined by comparison with a value-oriented shade guide (Vita Classical, Vita Zahnfabrik). Seventy-five third molars, of shade A2 or darker, free of cracks and/or caries, structural defects, or restorations were used in this study. The teeth were extracted and cleaned with periodontal curettes and an ultrasonic cleaner (Cristófoli, Campo Mourão, PR, Brazil) followed by prophylaxis with a rubber cup and pumice. The teeth were cleaned and stored in deionized water until use, for no more than 1 month. Staining protocol was not used before bleaching procedures to avoid interference in Raman analysis.

The crown was sectioned parallel to the buccal face to obtain a tooth slice ( $7 \mathrm{~mm} \times 7 \mathrm{~mm})$ using a diamond disc in a cutting machine (Isomet low speed, Buehler, Lake Forest, IL, USA). The enamel/dentin block was drawn from the flatter buccal surface on the cervical and middle thirds. Block with $4 \mathrm{~mm}$ in thickness were obtained, considering the distance between the enamel surface and pulp clamber dentin. These blocks were coupled to acrylic resin cylinders and randomly allocated and submitted to different bleaching protocols $(n=15)$ described in Table 1. The protocols using HP and VL alone or VL combined with HP were made according to the manufacturer's instructions. The ozonegenerating device (Ozone Generator Philozon Med Plus, Balneário Camburiú, SC, Brazil) was used with a $1 \mathrm{~L} / \mathrm{min}$ oxygen flow controlled by automatic regulation of system (self-regulation). Considering the maximum limit of $5 \%$ ozone in the oxygen/ozone mixture produced by the device, the ozone concentration dose was adjusted at $60 \mu \mathrm{g} / \mathrm{mL}$ to increase the effectiveness of the ozone treatment. The specimens were placed in a sealed package and were exposed to ozone gas for 20 minutes (10). For all protocols, two bleaching sessions were performed with 48 hours interval between them (11). The 
samples were stored at a controlled temperature $\left(37 \pm 1^{\circ} \mathrm{C}\right)$ in deionized water to avoid any interferences at mineral analysis.

Table 1. Bleaching protocols tested.

Group

Bleaching protocols

HP

35\% hydrogen peroxide* (Whiteness HP Automixx, FGM, Joinville, Santa Catarina, Brazil. The gel was applied on enamel for $40 \mathrm{~min}$. Subsequently, the bleaching gel was removed and enamel was washed with distilled water.

VL

Twenty cycles of 60 seconds irradiation from violet light with a wavelength of $405-410 \mathrm{~nm}$ (Bright Maxx Whitening Light Source, MMOptics, Ltda, São Paulo, Brazil), was performed on specimens. Each cycle involved one minute of irradiation followed by 30 seconds of rest. The equipment was positioned at $8 \mathrm{~cm}$ from the samples, with an angle of $90^{\circ}$. positioned at $8 \mathrm{~cm}$ from the samples, with an angle of $90^{\circ}$. After, HP was applied and more ten cycles were performed with gel on surface.

$\mathrm{OZ}$

The specimens were placed in a sealed package and was exposed to ozone gas for $20 \mathrm{~min}, 60$ microgram $/ \mathrm{mL}$ concentration and $1 \mathrm{~L} / \mathrm{min}$ flow using an ozone-generating device (Ozone Generator Philozon Med Plus, Balneário Camburiú, SC, Brazil).

$\mathrm{HP}+\mathrm{OZ} \quad$ After 10 minutes ozone exposure (OZ group), $\mathrm{HP}$ was applied by 10 minutes, the samples were washed with distilled water, and another 10 minutes of $\mathrm{OZ}$ application was performed.

*The average pH of bleaching gel (6.9) was measured using a pH meter (Adwa, Szeged, Hungary).

\section{Measurements of Color Change}

The colors of each specimen were measured using a visible/ultraviolet reflection spectrophotometer (Ci64UV, X-Rite, Grand Rapids, MI, USA) and rated according to the color system established by the Commission Internationale de L'Eclairage (CIE), which is based on the dimensions L* (white to black), $\mathrm{a}^{*}$ (red to green), and $\mathrm{b}^{*}$ (yellow to blue). The color was measured at baseline and 7 days after the end of the bleaching procedures by placing the specimens at the same position for both measurements. The specimens were positioned in focus on a clear acrylic stand, and measurements were performed with a standard illuminant D65, with wavelength ranging from 400 to $700 \mathrm{~nm}$, and with the specular light included (SPIN mode). Due to the spherical shape of the spectrophotometer, the object was diffusely illuminated, and the detector received the reflected light at $88^{\circ}$ with the enamel surface. The color measurements were performed in triplicate over a white background $\left(\mathrm{L}^{*}{ }_{\text {white }}=95.2, \mathrm{a}^{*}{ }_{\text {white }}=21.2, \mathrm{~b}^{*}{ }_{\text {white }}\right.$ $=50.3$ ), and the mean values were used for data analysis. The whitening indexes (WI) were calculated at baseline and after bleaching protocols using the following formula: $\mathrm{WI}=0.551 \mathrm{~L}^{*}-2.324 \mathrm{a}^{*}$ 1.1b*.(12) Overall color changes from baseline were calculated using both $\Delta \mathrm{E}_{\mathrm{ab}}$ and $\Delta \mathrm{E}_{00}$ formulas.(13) Until color measurements, the samples were stored at $37 \pm 1^{\circ} \mathrm{C}$ in deionized water.

\section{Raman Analysis}

Before and after undergoing the bleaching protocols, the enamel surface of specimens was analyzed using Raman spectroscopy (RFS 100/S, Bruker Inc., Karlsruhe, Germany). The analyses before treatment were used as control (baseline). To excite the spectra, a focused $1064.1 \mathrm{~nm}$ beam of an aircooled Nd:YAG laser source was used. The maximum incident laser power on the sample surface was $\sim 100 \mathrm{~mW}$ and the spectrum resolution was $4 \mathrm{~cm}^{1}$. The Raman spectra were obtained using 100 scans and one spectrum was collected for each sample, using a central point on the enamel surface. The lower limit of laser penetration depth was $\sim 500 \mathrm{~mm}$. The frequency of spectra ranged from $400-3000 \mathrm{~cm}^{-1} \mathrm{in}$ the region of interest, thereby allowing a characterization of both mineral (hydroxyapatite) and organic constituents. The analyzed peaks were performed in the following Raman vibrational stretching modes, corresponding to $431 \mathrm{~cm}^{-1}, 581 \mathrm{~cm}^{-1}, 960 \mathrm{~cm}^{-1}$ and $1025 \mathrm{~cm}^{-1}$ phosphate (PO), and carbonate (CA) (1070 $\left.\mathrm{cm}^{-1}\right) .(14)$ 
For the Raman analysis, the specimens were positioned over a glass slide in the sample holder compartment, and an IR354 lens collected radiation over $90^{\circ}$ on the enamel surface. The obtained spectra, in the readings before and after treatment, were analyzed using analytical software (Microcal Origin 5.0 Software, Inc., Northampton, MA, USA). The luminescent background was removed using baseline correction for each spectrum collected before performing relative comparison studies of organic and inorganic content. The spectra were corrected in baseline and then normalized by the mean. The band fitting of characteristic peaks was performed using a combined Gaussian and Lorentzian function to determine the exact position, peak intensities, and areas, as previously reported.(14)

\section{Atomic Force Microscope Analysis}

An atomic force microscope (AFM) SPM-9600 (Shimadzu, Tokyo, Japan) was used to evaluate the topography of specimens, within an area of $30 \mu \mathrm{m} \times 30 \mu \mathrm{m}$, scanning of $0.30 \mathrm{~Hz}$, in two different positions at the center of the sample. All AFM measurements were carried out with the tip working in AC-mode (tapping mode) and the mean values from AFM roughness ( $\mathrm{Sa}$ ) measurements were submitted to statistical analysis. The force between the AFM tip and the sample surface was kept constant by the microscope feedback system while the sample surface was scanned below the AFM tip and the vertical piezoelectric ceramic motion was recorded. Cantilevers with a constant spring of $48 \mathrm{~N} / \mathrm{m}$ and with monolithic silicon tips smaller than $10 \mathrm{~nm}$ radius (model Tap190Al-G, Sunnyvale, CA, USA) were used. The WSxMV 3.1 software (Gwyddion) transformed turned the obtained data into 3D images for subsequent analysis. The results were 3D versions of the images of the surface of each specimen made before and after the application of the bleaching techniques.

\section{Statistical analysis}

Data were tested for normal distribution (Shapiro-Wilk) and equality of variances (Levene's test), followed by parametric statistical tests. One-way ANOVA followed by the Tukey test was used for $\Delta \mathrm{E}_{\mathrm{ab}}$ and $\Delta \mathrm{E}_{00}$ parameters and ratio PO/CA. Two-way RM ANOVA was used for PO, CA, WI, and surface roughness parameters. The significance level was set at $95 \%$ for all analyses. All analyses were performed using the SigmaPlot.12.5 statistical software package (Systat Software Inc., Germany).

\section{Results}

\section{Color Change Measurement}

For WI data, two-way RM ANOVA on ranks, showed the assessment time, was significant $(\mathrm{P}<0.001)$. The results for WI are presented in Table 2. Similar WI values at baseline were observed between specimens allocated for each protocol, demonstrating that the randomization was able to balance the initial color of specimens among the treatments. The use of hydrogen peroxide increased WI either used alone or associated with ozone or violet light. Using ozone or violet light alone did not promote WI increase. One-way ANOVA demonstrated that the bleaching protocols affected the WI changes $(p<0.001)$. Mean WI change values demonstrated that clinically relevant changes were only observed in the presence of hydrogen peroxide. Compared to the use of hydrogen peroxide alone, only the association of this agent with ozone was able to significantly improve the mean values of WI increase.

Table 2 - Means of whitening indexes (standard deviation) according to assessment times and bleaching protocols $(\mathrm{n}=15)$.

\begin{tabular}{cccc}
\hline \multirow{2}{*}{ Bleaching protocols } & \multicolumn{2}{c}{ Assessment times } & WI changes \\
\hline $\mathrm{HP}$ & Baseline & After bleaching & \\
$\mathrm{VL}$ & $30.0(5.8) \mathrm{Ba}$ & $34.9(3.2) \mathrm{Aab}$ & $4.9(4.2) \mathrm{BC}^{*}$ \\
$\mathrm{OZ}$ & $30.8(5.8) \mathrm{Ba}$ & $31.5(6.7) \mathrm{Bb}$ & $0.7(1.8) \mathrm{D}$ \\
$\mathrm{HP}+\mathrm{VL}$ & $32.1(4.9) \mathrm{Ba}$ & $34.0(4.8) \mathrm{Bb}$ & $1.9(1.5) \mathrm{CD}$ \\
$\mathrm{HP}+\mathrm{OZ}$ & $31.0(7.6) \mathrm{Ba}$ & $37.5(5.4) \mathrm{Aab}$ & $6.5(3.9) \mathrm{AB}^{*}$ \\
\hline
\end{tabular}


For values of whitening index, different letters (uppercase for comparing the assessment times - in lines; lowercase for comparing bleaching protocols - in columns) indicate significant difference at Tukey`s test $(\mathrm{P}<0.05)$. For WI changes, different letters Tukey`s test $(\mathrm{P}<0.05)$. *WI changes beyond the acceptability threshold $(\mathrm{WI}=2.6)$.

One-way ANOVA showed that the bleaching protocol affected both $\Delta \mathrm{E}_{\mathrm{ab}}$ and $\Delta \mathrm{E}_{00}(\mathrm{p}<0.001$ for both outcomes). Table 3 presents the results of the overall color changes according to the bleaching protocols. The ozone-associated hydrogen peroxide presented the highest $\Delta \mathrm{E}_{\mathrm{ab}}$ values, and the violet light alone, the lowest. The hydrogen peroxide, either used alone or associated with violet light produced a similar $\Delta \mathrm{E}_{\mathrm{ab}}$. The use of ozone alone resulted in a similar $\Delta \mathrm{E}_{\mathrm{ab}}$ to both the hydrogen peroxide and the violet light. The highest overall color change was observed in the associated use of ozone and hydrogen peroxide when data of $\Delta \mathrm{E}_{00}$ were analyzed, but without statistical difference for the violet light-hydrogen peroxide association. However, the values of $\Delta \mathrm{E}_{00}$ observed for hydrogen peroxide alone were increased only when this whitener was associated with ozone. Either ozone or violet light used alone resulted in the lowest values of $\Delta \mathrm{E}_{00}$.

Table 3 - Means and standard deviation of color parameters of the teeth after bleaching $(n=15)$.

\begin{tabular}{ccc}
\hline Bleaching protocols & \multicolumn{1}{c}{$\boldsymbol{\Delta \mathbf { E } _ { \mathbf { a b } }}$} & $\boldsymbol{\Delta}$ \\
\hline$H P+O Z$ & $6.5 \pm 2.0 \mathrm{E}_{\mathbf{0}} \mathrm{A}^{*}$ & $4.7 \pm 1.5 \mathrm{~A}^{*}$ \\
$H P+V L$ & $4.6 \pm 2.1 \mathrm{~B}^{*}$ & $3.7 \pm 1.5 \mathrm{AB}^{*}$ \\
$H P$ & $4.0 \pm 1.6 \mathrm{BC}^{*}$ & $3.2 \pm 1.0 \mathrm{~B}^{*}$ \\
$O Z$ & $2.5 \pm 0.8 \mathrm{CD}$ & $1.8 \pm 0.5 \mathrm{C}^{*}$ \\
$V L$ & $2.3 \pm 1.3 \mathrm{D}$ & $1.8 \pm 1.0 \mathrm{C}^{*}$
\end{tabular}

Distinct letters indicate statistically significant difference at Tukey`s test $(\mathrm{P}<0.05)$. * Color changes beyond the acceptability threshold $\left(\triangle \mathrm{E}_{\mathrm{ab}}=2.66 ; \Delta \mathrm{E}_{00} 1.77\right)$.

The behavior of $\mathrm{L}^{*}, \mathrm{a}^{*}$, and $\mathrm{b}^{*}$ parameters according to the bleaching protocols and assessment times are shown in Figure 1. Some increase in lightness within the bleaching procedure was observed for the use of hydrogen peroxide associate with ozone and to the use of violet light alone, whereas a reduction in lightness was observed when only ozone was applied onto the enamel. In general, the bleaching protocols resulted in redness and yellowness reduction (except in the use of ozone alone).
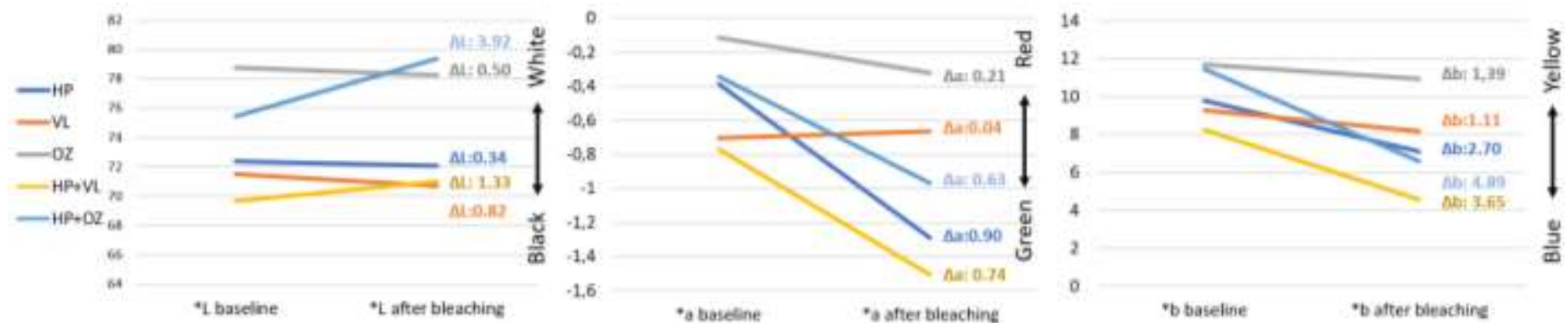

Figure 1. Baseline and after bleaching values of $\mathrm{L}^{*}, \mathrm{a}^{*}$ and $\mathrm{b}^{*}$

\section{Structural Chemical Analysis}

Table 4 shows the $\mathrm{Y}$ values for each peak before and after bleaching. The spectra for enamel surfaces and the results of peak area are shown in Figure 2. The two-way ANOVA of repeated measurements showed that five groups presented the same peak positions, but their intensities were different in the peak $1025 \mathrm{~cm}^{-1} \mathrm{PO}_{4}(\mathrm{P}=0.025)$ and $1070 \mathrm{~cm}^{-1} \mathrm{CO}_{3}^{-2}(\mathrm{P}<0.001)$ concerning time, with an increase after bleaching, regardless of the applied techniques (Figure 2). 
Table 4 - Means and standard deviation of $Y$ values for phosphate and carbonate peaks before and after bleaching

\begin{tabular}{|c|c|c|c|c|c|c|c|c|c|c|}
\hline & \multicolumn{5}{|c|}{ Baseline } & \multicolumn{5}{|c|}{ After Bleaching } \\
\hline \multirow{2}{*}{$\mathrm{HP}+\mathrm{OZ}$} & 0.032 & 0.036 & 0.305 & 0.016 & 0.072 & 0.032 & 0.036 & 0.302 & 0.017 & 0.081 \\
\hline & 0.003 & 0.001 & 0.011 & 0.001 & 0.001 & 0.004 & 0.002 & 0.006 & 0.001 & 0.002 \\
\hline$H P+V L$ & 0.031 & 0.037 & 0.31 & 0.016 & 0.081 & 0.029 & 0.036 & 0.298 & 0.016 & 0.09 \\
\hline$H P$ & 0.002 & 0.002 & 0.01 & 0.001 & 0.002 & 0.004 & 0.002 & 0.015 & 0.001 & 0.003 \\
\hline \multirow{2}{*}{$O Z$} & 0.034 & 0.038 & 0.302 & 0.016 & 0.074 & 0.032 & 0.037 & 0.301 & 0.017 & 0.079 \\
\hline & 0.003 & 0.002 & 0.011 & 0.001 & 0.001 & 0.002 & 0.002 & 0.007 & 0.001 & 0.001 \\
\hline
\end{tabular}
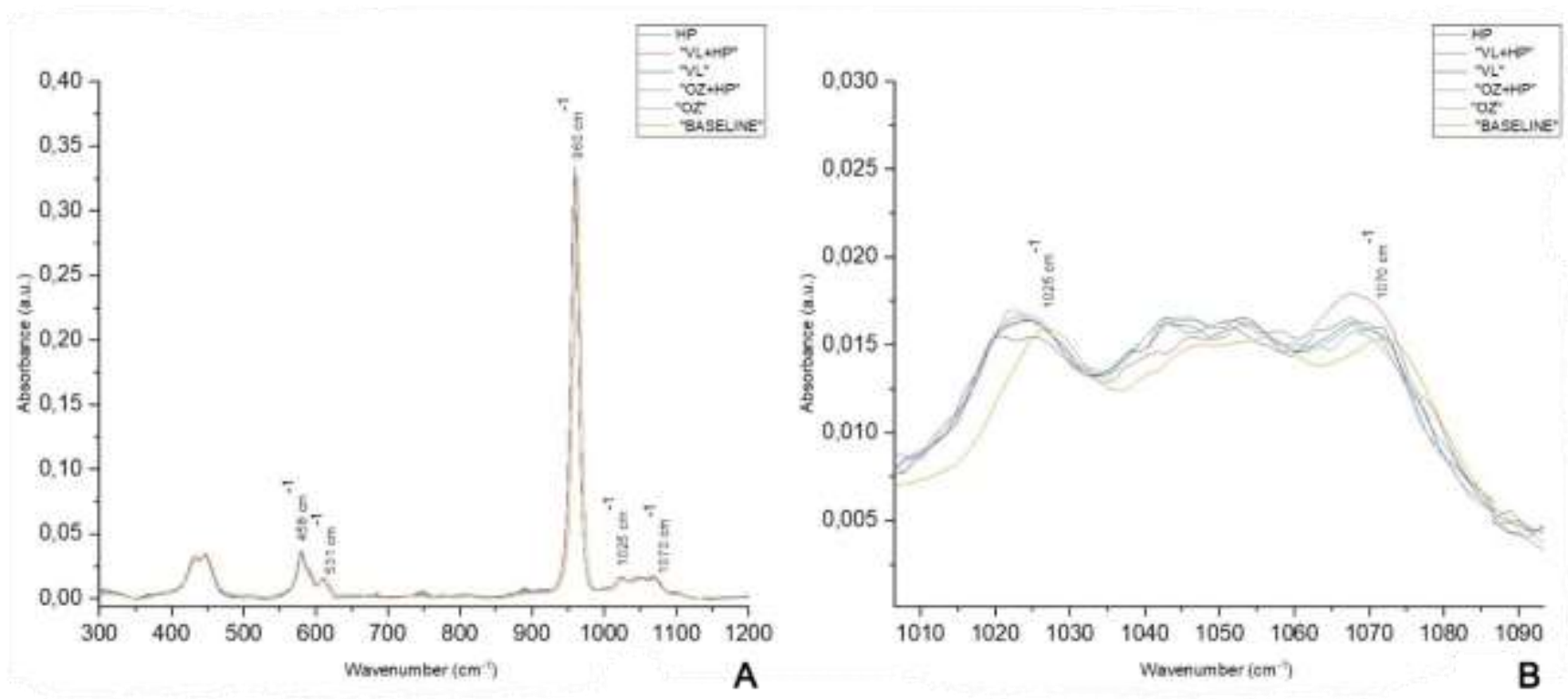

Figure 2. A. Typical Raman spectrum with the phosphate and carbonate peaks. B. Raman spectrum for peaks $1025 \mathrm{~cm}^{-1}-$ phosphate and $1070 \mathrm{~cm}^{-1}$ carbonate

For the phosphate peaks at $431 \mathrm{~cm}^{-1}, 581 \mathrm{~cm}^{-1}$, and $960 \mathrm{~cm}^{-1}$ there is no statistically significant difference among the bleaching protocols, their assessment time, and the interaction between them. The phosphate carbonate ratio for the peaks at 431,581 , and $960 \mathrm{~cm}^{-1}$ were reduced after bleaching, regardless of the group. The peak at $1025 \mathrm{~cm}^{-1}$ was not change in this analysis. 


\section{Surface roughness analysis}

The mean roughness values $(\mathrm{Sa})$ were similar among the treatment groups $(\mathrm{P}=0.171)$. Representative images were presented in Figure 3.

A
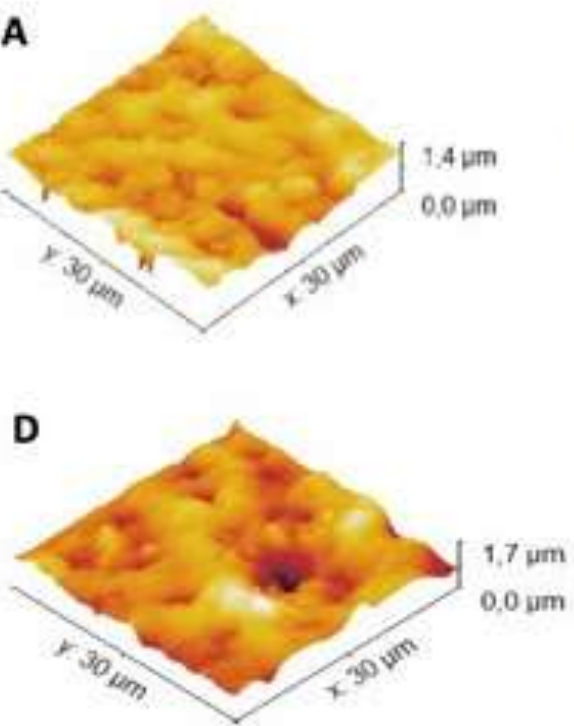
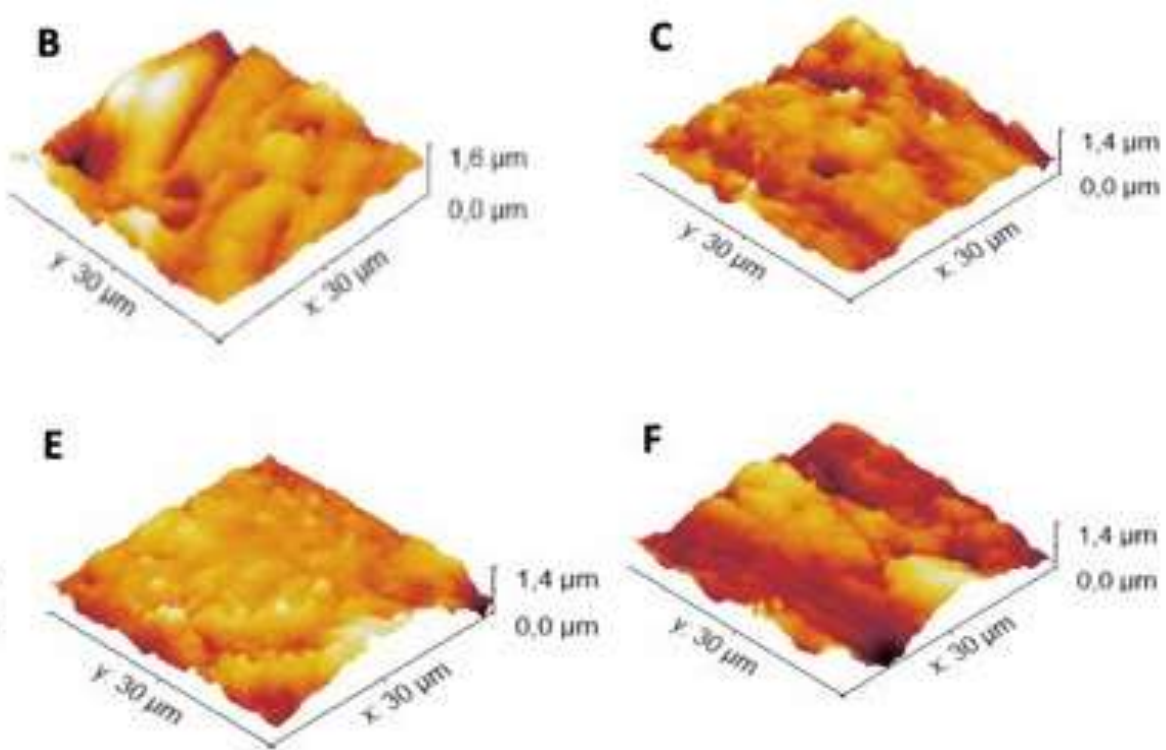

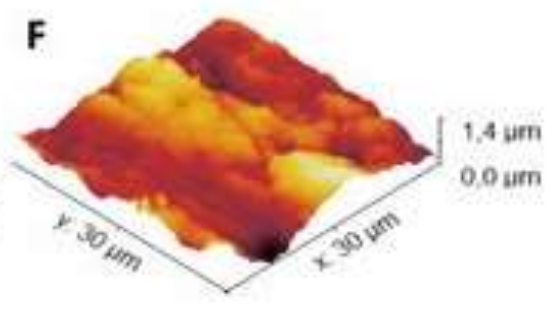

Figure 3. Atomic force microscopy images. A: Baseline; and sample submitted to: B. Hydrogen peroxide bleaching C. violet light bleaching; D. Violet light + hydrogen Peroxide bleaching E. Ozone bleaching F.Ozone +hydrogen peroxide bleaching.

\section{Discussion}

The use of alternative therapies that avoid the use of hydrogen peroxide in dental bleaching procedures is critical to reducing tooth sensitivity and preserving the structural normality of the dental substrate. However, we suggested that some techniques could be used to replace HP or applied in association with HP with some advantages such as improvement or maintenance in tooth whiteness results, longer stability time and color maintenance, reduction of sensitivity side effects dentin, and also toxicity to dental tissues, or even reduction of clinical time in the operative procedure should be observed in their uses, as they demand investment, whether in equipment, which often requires prior training or unused material from the routine way in the office.

This study evaluated five bleaching protocols, including the ozone and violet light associated or not to hydrogen peroxide, comparing their efficacy and results with the hydrogen peroxide gel used alone. The results were evaluated using the $\Delta \mathrm{E}_{\mathrm{ab}}, \Delta \mathrm{E}_{00}$, and WI, which describe color change on three color dimensions: $\mathrm{L}^{*}, \mathrm{a}^{*}$, and $\mathrm{b}^{*}$ (CIELab System). The values of these indexes could clinically identify color changes, proving the effectiveness of each bleaching procedure. $(10,15)$ Therefore, the first hypothesis of the study was rejected, as the use of ozone showed interference on the bleaching effectiveness when associated with hydrogen peroxide, improving all analyzed color parameters.

The ozone can be considered as an enhancer, an effect that could be observed not only by the change in $\Delta \mathrm{E}_{\mathrm{ab}}, \Delta \mathrm{E}_{00}$, of $\mathrm{b}^{*}$ values (blue/yellow pigment) and also WI, which strongly correlates to the perception of tooth whiteness with a clear interpretation: high positive values of the WI index indicate higher whiteness values. In this sense, it is assumed that a bleaching technique is efficient if it produces whiteness variation above the perceptibility threshold, whereas if the variation is above the acceptability threshold, the efficiency of the whitening technique will be both optimal and satisfactory for the patient. The WI difference was 9.0 (hardly acceptable)(15) when hydrogen peroxide was associated with ozone and 4.9 (fairly acceptable) when hydrogen peroxide was used alone.(15) The protocol using ozone associated with hydrogen peroxide has reduced the use of peroxide time, as described in Table 1 . The time of gel use was reduced by $1 / 4$ when compared to the peroxide alone, and even then, satisfactory alterations were observed regarding WI, $\triangle \mathrm{E}_{\mathrm{ab}}$, and $\triangle \mathrm{E}_{00}$. Using a gel shorter time on the tooth surface would minimize structure risks caused by the bleaching procedure. Ozone is an unstable gas that rapidly releases nascent oxygen molecules to form oxygen that can oxidize the components responsible for tooth discoloration. Chromophore groups may be broken by ozone, forming smaller molecules, resulting in a 
tooth bleaching effect by one of the following mechanisms: bonding, substitution, or cleavage. (16) Besides that, ozone use has been associated with no sensitivity pain after bleaching with hydrogen peroxide. $(6-8,16)$ Comparing the clinically efficacy of $35 \%$ hydrogen peroxide with and without ozone in 60-second-applications, the association of the two products showed more satisfactory results, whiter teeth, and higher $\mathrm{L}$ values. $(7,8,16)$

However, observing the WI results after the isolated ozone bleaching protocol, such values were considered only perceptible, (15) not reaching acceptability thresholds; (15) and also low values of $\triangle \mathrm{Eab}$ and $\triangle \mathrm{E} 00$ were observed, suggesting low visual acceptability, (15) in the degree of whitening induced by this group. The efficacy of short-term exposure to ozone has been demonstrated in different studies as a controversial method. One of them used ozone to treat stains caused by tetracycline, being effective in three to five minutes at a concentration of $2100 \mathrm{ppm} \pm 5 \%$ and $615 \mathrm{cc} / \mathrm{min} 1 \mathrm{flow}$ rate.(9) Another laboratory study that applied a similar ozone concentration and flow rate, found it has no synergistic effect when used simultaneously with hydrogen peroxide.(17) Thus, the most effective ozone bleaching protocol is not well-established yet, and these differences such as gas pressure, time, and use can alter results, and effectiveness may be associated to these factors. Thus, further studies would be needed in order to better clarify gas and pressure parameters for safe clinical use with patients.

The proposal of the use of violet light is based on the advantage that light sources bring to the decomposition acceleration, forming a greater amount of free radicals.(18) In our study, the protocol used to violet LED only also prompted a bleaching effect, although it was less marked, with WI $(12,15)$ and color changes $(\triangle \mathrm{Eab}=2.66 ; \triangle \mathrm{E} 001.77)(10)$ to whom the acceptability threshold. In a recent in vitro study, the technique with the VL without gel showed bleaching potential, but with a larger number of sessions/applications(5). The present study indicated a tendency towards bleaching when associated with HP, however, this potential effect was statistically similar compared to conventional technique(5). This association is not necessary maybe possibly because the high availability of peroxides in the dental tissue masked the action of the violet light. Moreover, if a larger number of sessions had been conducted in the present study, some bleaching potential could be found. However, this VL protocol can increase the session length and the cost of the procedure.

There are few studies using violet light as a whitening protocol, and although studies claim color change for the use of violet light alone, such studies used previously pigmented teeth in their studies, (5) and according to authors, the results may suggest that the light removed the pigment by the leaching method. We also emphasize that the results obtained in this study were different when compared to conventional techniques, being necessary to increase the number of sessions or even associate it with the whitening gel to obtain desirable results. (5) Another hypothesis for the divergence of results in the literature refers to the possibility of the results being influenced by complementary factors, such as $\mathrm{pH}$, or even by temperature, exposure time, and even repeated application. Thus, we believe that studies using violet light changing $\mathrm{pH}$, or comparing previously pigmented and non-pigmented teeth, would be interesting to analyze this hypothesis, as well as to analyze different protocols of time or more sessions of application of violet light. Therefore, there is still no evidence that violet light improves the whitening efficacy, which suggests an increase in the cost of the procedure with no benefit in dental settings.

Here, we showed changes on the enamel structure after bleaching. To establish the effectiveness of bleaching, the efficiency must be combined with the lack of change to the tooth substrate. Therefore, the second hypothesis was rejected, because all bleaching protocols can modify the mineral composition of the enamel after bleaching; however, they were not able to modify the surface roughness, despite a previous study suggested that repeating the bleaching procedure may increase $S$. Mutans adhesion.(19)

The $\mathrm{pH}$ of the bleaching gel was considered to be responsible for the change to the enamel, and gels at high concentrations, with lower $\mathrm{pH}$ and lower stability, tend to promote greater changes in the dental structure.(3) This is probably the case when bleaching products substances of acid $\mathrm{pH}$ of at least 5.2 , because this $\mathrm{pH}$ is sufficient to lead to enamel demineralization, with changes in mineral and organic composition. However, the bleaching product used in the present study was Whiteness HP Automix Whitening, as it presents a more neutral $\mathrm{pH},(3)$ and presents a source of soluble calcium in the bleaching agent formulation, which aims at the maintenance of dental enamel integrity when it is being bleached.(20) Mineral loss is minimized by the addition of $\mathrm{F}$ and $\mathrm{Ca}$ to bleaching agents.(21) Therefore, this may be the reason for the lack of increase of rough surface structures on the enamel. This shows that the protocols used are safe regarding the change in surface morphology. Protocols in which it is used only violet light or ozone are not able to change the enamel surface, as the bleaching procedure is not effective. 
Raman spectroscopy is considered a state-of-the-art technique to evaluate chemical changes. This nondestructive method is used to analyze the molecular composition of different substances and is ideal for the analysis of inorganic surface tissues (e.g. the concentration of molecules of phosphate and carbonate). Information about minerals may be obtained through the observation of their energy via the excitation of vibrational modes.(22) The analysis of samples in Raman can establish the chemical and molecular compositions of the enamel, through peaks that indicate the presence of carbonate and phosphate. (23)

In this study, all bleaching protocols showed peaks of carbonate and phosphate. Gaps are evident between the hydroxyapatite crystals, making the enamel molecules susceptible to substitutions. Carbonate ions can replace hydroxyl or phosphate ions.(22) The carbonate constitutes $2-5 \%$ of the enamel and can be considered as an important factor that influences its mechanical properties. The carbonate increase reduces the enamel's crystallinity, hardness, and modulus. The lower its crystallinity, the more susceptible to the acid attack, caries, and demineralization it becomes, leading to smaller surface roughness changes.(23) On the other hand, the enamel surface phosphate increase presents beneficial effects to the chemical structure. Phosphates have been proven to exert cariostatic action, reduce enamel solubility, and act as a buffer in neutralizing salivary, bacterial, plaque, and food $\mathrm{pH}$ values. They interfere with enzymatic processes on enamel surfaces to increase host resistance, decrease bacterial adhesion, and interfere with synthesis of extracellular polysaccharide formation. Finally, phosphates maintain plaque calcium and phosphorus level.(24) These chemical changes may be related to both the interaction of the gel with the surface and the possibility of ozone or light acting to promote a molecular rearrangement, which could increase the phosphate and carbonate peaks found in this study, but more studies are required to verify the clinical significance of these changes.

We are aware of the limitations of our study, as this was an in vitro experimental model, although such studies are widely used to analyze the effectiveness of tooth whitening. We also emphasize that the new techniques suggested do not yet have pre-established protocols that prove their effectiveness or that cancel it, being safer to propose and re-establish new protocols in these types of study, which justifies not only the performance of this work but also corroborates for the carrying out of new studies.

In summary, this study demonstrated alone that alternative protocols using violet light and ozone were not capable to promote isolated effects on the color of enamel, compared to the traditional technique. The association of peroxide is essential for these techniques to be effective; however, the association with ozone presents an effective bleaching improvement and also reduces the exposure of dental tissues to the gel with a reduction in the clinical time of the procedure. Also, the bleaching did not influence the enamel roughness, but it increased intensities in the peaks at $1025 \mathrm{~cm}^{-1}\left(\mathrm{PO}_{4}\right)$ and 1070 $\mathrm{cm}^{-1}\left(\mathrm{CO}_{3}^{-2}\right)$, regardless of the applied technique. The present study had some limitations. Although it was not the aim of the present study, it is not clear whether the clinical use of ozone maintains the chromatic stability or if it would remain over longer periods. Considering that these agent-free oxidizing are new bleaching alternatives, further investigation is required to investigate the possible adverse effects concerning adhesion, the dentin's mechanical properties, as well as any possible biological effects.

Acknowledgment: This study was financed in part by the Coordination of Superior Level Staff Improvement - CAPES (Finance Code 001), The Brazilian National Council for Scientific and Technological Development (CNPq) and the Research Supporting Foundation of Minas Gerais State FAPEMIG.

\section{Resumo}

O objetivo deste estudo foi avaliar o efeito clareador e físico-químico no esmalte de luz violeta e ozônio, associado ou não ao peróxido de hidrogênio, comparado a 35\% de peróxido de hidrogênio. Blocos de esmalte-dentina de molares humanos foram alocados aleatoriamente para receber um dos seguintes protocolos de clareamento $(\mathrm{n}=15)$ : $(\mathrm{HP})$ peróxido de hidrogênio a $35 \%$, (VL) luz violeta, (OZ) ozônio, a associação entre peróxido de hidrogênio com ozônio (HP+OZ) ou luz violeta (HP+VL). Todos os protocolos foram realizados em duas sessões, com intervalo de 48 horas entre eles. A cor (espectrofotômetro) e a composição mineral (espectroscopia Raman) do dente foram medidas antes e após os procedimentos de clareamento. As alterações de cor foram calculadas por $\Delta \mathrm{E}_{\mathrm{ab}} \mathrm{e} \Delta \mathrm{E}_{00}$, e o índice de brancura foram calculados. A rugosidade da superfície das amostras clareadas foi medida por microscópio de força atômica. Os dados foram analisados por ANOVA One way ou ANOVA two way 
de medidas repetidas seguida pelo teste de Tukey $(\alpha=0,05)$. Os menores valores de alterações de cor (medidos por WI, $\triangle \mathrm{E}_{\mathrm{ab}}$ ou $\triangle \mathrm{E}_{00}$ ) foram observados para VL e OZ usados na ausência de HP. VL associada ao HP não foi capaz de melhorar as alterações de cor observadas com o uso do HP, mas a combinação de $\mathrm{OZ}$ e HP produz as maiores alterações de cor. Independentemente do protocolo de clareamento, o esmalte clareado apresentou maiores teores de $\mathrm{PO}_{4} \mathrm{e} \mathrm{CO}_{3}^{-2}$ do que os observados inicialmente. Não foi observada diferença significativa entre os protocolos de clareamento testados em relação à rugosidade da superfície do esmalte. É possível concluir que a VL ou o OZ tiveram efeitos reduzidos na mudança de cor do esmalte quando usados sozinhos. A terapia com OZ melhorou o efeito clareador do HP.

\section{References}

1. Rezende M, Loguercio AD, Kossatz S, Reis A. Predictive factors on the efficacy and risk/intensity of tooth sensitivity of dental bleaching: A multi regression and logistic analysis. J Dent [Internet]. 2016;45:1-6. Available from: http://dx.doi.org/10.1016/j.jdent.2015.11.003

2. Markowitz K. Pretty painful: Why does tooth bleaching hurt? Med Hypotheses [Internet]. 2010;74(5):835-40. Available from: http://dx.doi.org/10.1016/j.mehy.2009.11.044

3. Trentino AC, Soares AF, Duarte MAH, Ishikiriama SK, Mondelli RFL. Evaluation of pH levels and surface roughness after bleaching and abrasion tests of eight commercial products. Photomed Laser Surg. 2015;33(7):372-7.

4. Rezende M, Chemin K, Vaez SC, Peixoto AC, Rabelo J de F, Braga SSL, et al. Effect of topical application of dipyrone on dental sensitivity reduction after in-office dental bleaching: A randomized, triple-blind multicenter clinical trial. J Am Dent Assoc. 2018;149(5):363-71.

5. Gallinari M, Fagundes T, da Silva L, de Almeida Souza M, Barboza A, Briso A. A New Approach for Dental Bleaching Using Violet Light With or Without the Use of Whitening Gel: Study of Bleaching Effectiveness. Oper Dent. 2019;44(5):521-9.

6. Rastelli AN de S, Dias HB, Carrera ET, de Barros ACP, dos Santos DDL, Panhóca VH, et al. Violet LED with low concentration carbamide peroxide for dental bleaching: A case report. Photodiagnosis Photodyn Ther. 2018;23:270-2.

7. Al-Omiri MK, Al Nazeh AA, Kielbassa AM, Lynch E. Randomized controlled clinical trial on bleaching sensitivity and whitening efficacy of hydrogen peroxide versus combinations of hydrogen peroxide and ozone. Sci Rep. 2018;8(1):1-10.

8. Dietrich L, de Assis Costa MDM, Blumenberg C, Nascimento GG, Paranhos LR, da Silva GR. A meta-analysis of ozone effect on tooth bleaching. Sci Rep [Internet]. 2021 Dec 23 [cited 2021 Jul 26];11(1):13177. Available from: http://www.nature.com/articles/s41598-021-92733-8

9. Tessier, J; Rodriguez, PN; Lifshitz, F; Friedman, SM; Lanata E. The use of ozone to lighten teeth. An experimental study. Acta Odontol Latinoam. 2010;23(2):84-9.

10. Paravina RD, Ghinea R, Herrera LJ, Bona AD, Igiel C, Linninger M, et al. Color difference thresholds in dentistry. J Esthet Restor Dent. 2015;27(S1):S1-9.

11. De Paula EA, Nava JA, Rosso C, Benazzi CM, Fernandes KT, Kossatz S, et al. In-office bleaching with a two- and seven-day intervals between clinical sessions: A randomized clinical trial on tooth sensitivity. J Dent. 2015;43(4):424-9.

12. Pérez MDM, Ghinea R, Rivas MJ, Yebra A, Ionescu AM, Paravina RD, et al. Development of a customized whiteness index for dentistry based on CIELAB color space. Dent Mater [Internet]. 2016;32(3):461-7. Available from: http://dx.doi.org/10.1016/j.dental.2015.12.008

13. Miotti LL, Santos IS, Nicoloso GF, Pozzobon RT, Susin AH, Durand LB. The use of resin composite layering technique to mask discolored background: A CIELAB/CIEDE2000 analysis. Oper Dent. 2017;42(2):165-74.

14. Taube F, Marczewski M, Norén JG. Deviations of inorganic and organic carbon content in hypomineralised enamel. J Dent. 2015;43(2):269-78.

15. Pérez MM, Herrera LJ, Carrillo F, Pecho OE, Dudea D, Gasparik C, et al. Whiteness difference thresholds in dentistry. Dent Mater. 2019 Feb;35(2):292-7.

16. AL-Omiri MK, Hassan RSA, AlZarea BK, Lynch E. Effects of combining ozone and hydrogren peroxide on tooth bleaching: A clinical study. J Dent. 2016;53:88-93.

17. Zanjani VA, Ghasemi A, Torabzadeh H, Jamali M, Razmavar S, Baghban AA. Bleaching effect of ozone on pigmented teeth. Dent Res J (Isfahan). 2015;12(1):20-4. 
18. Maran BM, Ziegelmann PK, Burey A, de Paris Matos T, Loguercio AD, Reis A. Different lightactivation systems associated with dental bleaching: a systematic review and a network meta-analysis. Clin Oral Investig. 2019;23(4):1499-512.

19. Khoroushi M, Shirban F, Doustfateme S, Kaveh S. Effect of three nanobiomaterials on the surface roughness of bleached enamel. Contemp Clin Dent. 2015;6(4):466-70.

20. Borges AB, Torres CRG, De Souza PAB, Caneppele TMF, Santos LFTF, Magalhães AC. Bleaching gels containing calcium and fluoride: Effect on enamel erosion susceptibility. Int J Dent. 2012;2012.

21. Cavalli V, Rosa DA da, Silva DP da, Kury M, Liporoni PCS, Soares LES, et al. Effects of experimental bleaching agents on the mineral content of sound and demineralized enamels. J Appl Oral Sci. 2018;26:e20170589.

22. Vargas-Koudriavtsev T, Herrera-Sancho ÓA. Effect of tooth-bleaching on the carbonate concentration in dental enamel by Raman spectroscopy. J Clin Exp Dent. 2017;9(1):e101-6.

23. Xu, C; Reed, R; Gorski, JP; Wang, Y; Walker M. The Distribution of Carbonate in Enamel and its Correlation with Structure and Mechanical Properties. J Mater Sci. 2011;47(23):8035-43.

24. Venkatesan S, Narayan G, Ramachandran A, Indira R. The effect of two bleaching agents on the phosphate concentration of the enamel evaluated by Raman spectroscopy: An ex vivo study. Contemp Clin Dent. 2012;3(6):172.

Received: $26 / 09 / 2020$

Accepted: 29/09/2021 